\title{
Quantification and Analysis of Microplastics in Farmland Soils: Characterization, Sources, and Pathways
}

\author{
Hoda Fakour ${ }^{1, * \mathbb{D}}$, Shang-Lien Lo ${ }^{2,3}$, Nathan Thadeo Yoashi ${ }^{1}$, Angelbetter Marselian Massao ${ }^{1}$, \\ Nelson Naboth Lema ${ }^{1}$, Fezile Bethusile Mkhontfo ${ }^{1}$, Patrick Chris Jomalema ${ }^{1}$, Nasra Shabani Jumanne ${ }^{1}$, \\ Bright Hubert Mbuya ${ }^{1}$, James Travor Mtweve ${ }^{1}$ and Moslem Imani ${ }^{4}$
}

1 International College of Practice and Education for the Environment, International Program for Sustainable Development, Chang Jung Christian University, No.1, Changda Rd., Gueiren District, Tainan City 71101, Taiwan; nathanthadeo@gmail.com (N.T.Y.); 107b22150@mailst.cjcu.edu.tw (A.M.M.); 108b21521@mailst.cjcu.edu.tw (N.N.L.); 107b22187@mailst.cjcu.edu.tw (F.B.M.); 107b22230@mailst.cjcu.edu.tw (P.C.J.); 107b22212@mailst.cjcu.edu.tw (N.S.J.); 108b21558@mailst.cjcu.edu.tw (B.H.M.); 107b22203@mailst.cjcu.edu.tw (J.T.M.)

2 Graduate Institute of Environmental Engineering, National Taiwan University, No.1, Sec.4, Roosevelt Rd., Taipei 106, Taiwan; sllo@ntu.edu.tw

3 Water Innovation, Low-Carbon and Environmental Sustainability Research Center, College of Engineering, National Taiwan University, Taipei 106, Taiwan

4 Department of Geomatics Engineering, National Cheng Kung University, No.1, University Road, Tainan City 701, Taiwan; moslem.imani62@gmail.com

* Correspondence: hfakour@mail.cjcu.edu.tw; Tel.: +886-6-2785123

Citation: Fakour, H.; Lo, S.-L.; Yoashi, N.T.; Massao, A.M.; Lema, N.N.; Mkhontfo, F.B.; Jomalema, P.C.; Jumanne, N.S.; Mbuya, B.H.; Mtweve, J.T.; et al. Quantification and Analysis of Microplastics in Farmland Soils: Characterization, Sources, and

Pathways. Agriculture 2021, 11, 330. https: / / doi.org/10.3390/ agriculture11040330

Received: 5 March 2021

Accepted: 7 April 2021

Published: 8 April 2021

Publisher's Note: MDPI stays neutra with regard to jurisdictional claims in published maps and institutional affiliations.

Copyright: (c) 2021 by the authors. Licensee MDPI, Basel, Switzerland. This article is an open access article distributed under the terms and conditions of the Creative Commons Attribution (CC BY) license (https:// creativecommons.org/licenses/by/ $4.0 /)$.
Abstract: While microplastics (MPs) have been identified extensively in aquatic ecosystems, their presence remains largely unexplored in soil ecosystems. Considering the potential effect of MPs on soil biodiversity and function, the present study investigated and analyzed the abundance and characteristics of MPs in soil profile. Taking soil samples from Tainan city farms, as one of the hotspots of agricultural practices in Taiwan, concentrations, types, compositions, pathways, and sources of MPs in farmland soils were quantified. Results showed that MPs were found in all soil samples in different depths ranging from 12-117 items $/ \mathrm{m}^{2}$ and MP abundance in farms adjacent to the suburban roads was about three times more than in enclosed farms separated from roads. Fragment and fibers were the main forms and low-density polyethylene was the dominant polymer of detected MPs. Historical land use, extensive application of plastic mulch, and utilization of fruit protection foams were identified as the main sources of MPs in farmlands. This study identifies the presence of MP emissions in farmland soils and investigates its features, which could serve as a framework for future studies into the ecological effects of MPs in the terrestrial environment.

Keywords: microplastics; farmland; soil; polyethylene; fibers; fragments; foams

\section{Introduction}

Plastic products are commonly used in daily life due to their low cost, malleability, and durability. Over the last 50 years, global plastic production has reached 9.1 billion tons, with an average annual growth rate of $8.7 \%$ [1]. Owing to massive processing and inefficient management, the plastic waste problem is unquestionably a major environmental concern. Despite the fact that the rate of plastic recycling is increasing and most plastic products and their residues are still released into the environmen; in 2015, for example, an estimated 250 million tons of plastics were released into the ocean [2]. Moreover, UV radiation, wind or water erosion, and other physical, chemical, and biological drivers can degrade plastic litter in the environment, resulting in smaller plastic debris [3].

Meso-, micro-, and nanoplastic particles are generally defined as $<25 \mathrm{~mm}-5 \mathrm{~mm}$, $5 \mathrm{~mm}-1 \mu \mathrm{m}$, and $<1 \mu \mathrm{m}$, respectively [4], and they can originate from primary or secondary production [5]. 
Microplastic (MP) pollution, which consists of wide range of different types and size, was first found in marine environments; as a result, several studies have focused on the origin, occurrence, and fate of marine MPs and their effects on aquatic life [6,7]. Given that most plastic waste is generated and emitted on land, it's surprising that MP research has only recently extended to terrestrial environments, where soils can be a substantial long-term sink for MP particles [8]. Urban and agricultural soils are considered to be particularly vulnerable to MP emissions as they are the epicenter of human activities, and consequently, MP input routes [9]. For many organisms, the most common route of plastic-mediated contaminant uptake is by ingestion. Not only is plastic waste eaten by more than 180 species, but also a positive correlation was found between the mass of consumed plastic and the concentration of polychlorinated biphenyls (PCBs) in birds. Since plastics can accumulate PCBs, this correlation suggests that contaminants can be transferred to other species through plastic particles [9]. Moreover, a recent study by Li et al. [10] on the measurement of MPs uptake by plants demonstrated the uptake and transport of polystyrene (PS) microbeads by plant roots and the in vivo distribution into the stem and leaves. MP can reach the soil as primary MP from industrial products through sludge application [11] or as secondary MP from plastic mulch degradation, which is also a common practice in agricultural activities in many countries, including Taiwan.

Though the advantages of mulching for enhancing yield and crop growth have long been recognized [12], the use of plastic mulch in agriculture has increased dramatically globally in the last ten years. This improvement is due to benefits such as increased soil temperature, reduced weed burden, maintained moisture, reduced certain insect pests, increased crop yields, and more productive use of soil nutrients [13]. Conventional polyethylene (PE) films are the predominant mulching products consist of low-density polyethylene (LDPE), linear low-density polyethylene (LLDPE), and high-density polyethylene (HDPE) [14,15].

Plastic goods are a mass product in the economy and in our daily lives due to a wide variety of useful attributes [16]. However, the widespread use of plastics, such as in the packaging industry, has led to the widespread distribution of plastics in natural sinks such as the oceans and soils $[17,18]$. Furthermore, the use of bio-waste as fertilizer, especially composted organic material, can be a significant route for plastic to enter the soil. Inefficient waste isolation, such as ignoring plastic labels and packages derived from fruits and vegetable protection covers in bio-waste processing, may leave some plastic particles, some of which can end up in compost and degrade to MPs [19]. Furthermore, even biodegradable plastics take longer to decompose and a consistently high temperature is also required [20].

Another less discussed source of MP with a special application in the packaging industry is the fruit package expanded polyethylene (EPE) foam net used for the fruit package during the growing season and to shield it from damage. Not only can foam packaging extend the shelf life of organic products by preserving the physicochemical properties of the fruit [21], but EPE foam is also inexpensive to manufacture, highly lightweight, damage-resistant, waterproof, and a cost-effective product. In fact, fruit-packing EPE foam net is a new type of soft packing material called pearl cotton, where the base polymer for EPE foams range from LDPE to HDPE [22]. Because of these characteristics, it is commonly used in agricultural practices for better aesthetics, efficiency, and hygiene in cultivation, transit, and handling. Fruit-protected foam (e.g., for guava) is used by many Taiwanese farmers because of its various advantages. Unfortunately, because of these characteristics, it is prone to potential problems in agricultural activities. EPE foam is light and quickly fragmented and swept away by wind and human activity, and it becomes brittle when exposed to UV rays in sunlight, where it is burrowed into the soil media by invertebrates, resulting in contamination of farmlands. Furthermore, several farmers will add another layer of transparent plastic to EPE foam to improve its fruit safety quality, and many of these items will be left on the farms after harvesting. 
In addition, many urban resident farmers cultivate their food on land near the road, along with roads and strips of land. They also make use of the public services for power lines or rail tracks. While roadside farming has some particular benefits, such as making it easier for the farm to take crops, fertilizers or water, and making it easier to sell agricultural products, farms situated nearby roads are more likely to experience different environmental contamination. In fact, street or road dust is an important pollution source that consists of a diverse combination of materials consisting of atmospheric deposits, garbage, car tires, and particulate matter that have been contaminated by diffuse sources [23]. Although a large number of pollutants have been confirmed in roadside soil, there are few records of MP abundance in such dust, which could be a major transport phase. Preliminary research in Iran revealed up to $900 \mathrm{MPs}$ in $15 \mathrm{~g}$ of street dust samples [24].

Moreover, tire wear particles generated by the abrasion of tire tread against road surfaces have recently been recognized to be a major contributor of MP emissions to the environment [25]. In a study by Knight et al. [26], the greatest abundance of tire wear particles in the natural environment was found in the soil beneath the expressway bridge rather than the river or estuary sediment. Several primary pathways such as atmospheric fallout, direct road, stormwater run-off, and treated wastewater effluent assumed to be responsible for carrying tire wear particles into the natural ecosystem. Sommer et al. [25] demonstrated that tire-derived MPs are composed of not just the original rubber core with its different additives (e.g., $\mathrm{Al}, \mathrm{Ti}, \mathrm{Fe}, \mathrm{Zn}, \mathrm{Cd}, \mathrm{Sb}$, or $\mathrm{Pb}$ ), but also potentially hazardous metals and metalloids found in the attached brake-abrasion particles (e.g., $\mathrm{Al}, \mathrm{Fe}, \mathrm{Cu}, \mathrm{Sb}$, or $\mathrm{Ba}$ ). The presence of these additional materials in the encrustment increases the risk of environmental harm caused by tire-wear particles [25].

Knowledge of MPs in soils is currently very low and investigating the contamination properties of soil MPs is still a big challenge [27]. Soil MP has been recently acknowledged by research communities and increasing number of researches are being performed to evaluate the potential MP source and pathways in soil and solid mediums. MP accumulating in agricultural soils as a result of sewage sludge applications was studied by Corradini et al. [28] indicating that that MP counts increase over time where successive sludge applications are performed. In another study by Berriot et al. [29], the plastic contamination in agricultural soil in Spain and the ingestion of plastic by sheep was assessed where the potential transport of MPs due to a herd of 1000 sheep was estimated to be $\sim 10^{6}$ particles ha ${ }^{-1} \mathrm{y}^{-1}$. Table 1 summarizes the most recent studies on MP contamination in agricultural soil samples.

Table 1. Recent studies on MP identification in agricultural soils.

\begin{tabular}{|c|c|c|c|c|c|c|c|}
\hline Region & MP Source & $\begin{array}{l}\text { Sampling } \\
\text { Depth }\end{array}$ & $\begin{array}{c}\text { No. of Soil Samples } \\
\text { (Excluding Control } \\
\text { Samples) }\end{array}$ & Main Extraction Method & $\begin{array}{l}\text { Identification } \\
\text { Method }\end{array}$ & Unit & Reference \\
\hline Chile & sludge application & $0-25 \mathrm{~cm}$ & 93 & $\begin{array}{c}\text { Centrifuge, density } \\
\text { separation by } \mathrm{NaCl} \text { and } \\
\mathrm{ZnCl}_{2}\end{array}$ & $\begin{array}{l}\text { Stereo } \\
\text { microscope }\end{array}$ & $\begin{array}{l}\text { Particles/5 } \\
\mathrm{g}^{-1} \text { dry } \\
\text { weight }\end{array}$ & [28] \\
\hline China & pig manure & $\sim 20 \mathrm{~cm}$ & 20 & $\begin{array}{c}\text { Continuous air-flow } \\
\text { flotation separation, } \\
\text { Density separation by } \\
\mathrm{NaCl}\end{array}$ & $\begin{array}{c}\text { Stereo } \\
\text { microscope, } \\
\text { ATR-FTIR, } \\
\text { scanning } \\
\text { electron } \\
\text { microscope } \\
\text { (SEM) }\end{array}$ & $\begin{array}{c}\text { Particles } / \mathrm{kg} \\
\text { dry weight }\end{array}$ & [30] \\
\hline China & plastic mulching & $20 \mathrm{~cm}$ & 20 & $\begin{array}{l}\text { Wet sieving, density } \\
\text { separation, carbonation }\end{array}$ & $\begin{array}{l}\text { SEM, } \\
\text { ATR-FTIR }\end{array}$ & $\begin{array}{l}\text { Numbers } / \mathrm{kg} \\
\text { dry mass }\end{array}$ & [31] \\
\hline China & $\begin{array}{l}\text { Large traffic flow, } \\
\text { domestic wastes, and } \\
\text { agricultural activities }\end{array}$ & top $5 \mathrm{~cm}$ & 20 & $\begin{array}{l}\text { Density separation by } \\
\qquad \mathrm{ZnCl}_{2}\end{array}$ & $\begin{array}{c}\text { Stereo } \\
\text { microscope, } \\
\text { micro-Raman } \\
\text { spectroscopy }\end{array}$ & $\begin{array}{l}\text { Items } / \mathrm{kg} \\
\text { dry weight }\end{array}$ & [32] \\
\hline Spain & plastic mulching & $0-10 \mathrm{~cm}$ & 9 & $\begin{array}{l}\text { Centrifuge, ultrasonic } \\
\text { bath }\end{array}$ & $\begin{array}{l}\text { Stereo } \\
\text { microscope }\end{array}$ & $\begin{array}{l}\text { Particles } / \mathrm{kg} \\
\text { dry matter }\end{array}$ & [29] \\
\hline Germany & $\begin{array}{l}\text { application of manure, } \\
\text { littering, mulching, and } \\
\text { silage }\end{array}$ & $\begin{array}{c}0-10 \mathrm{~cm} \\
10-20 \mathrm{~cm} \\
\text { and } 20-30 \\
\mathrm{~cm}\end{array}$ & 540 & Wet sieving & $\begin{array}{l}\text { Stereo } \\
\text { microscope, } \\
\text { FTIR }\end{array}$ & $\begin{array}{l}\mathrm{MP} / \mathrm{kg} \text { dry } \\
\text { weight }\end{array}$ & [33] \\
\hline Taiwan & $\begin{array}{l}\text { Historical fish farming, } \\
\text { fruit protective foam, } \\
\text { nearby roads, mulch, } \\
\text { plastic debris }\end{array}$ & $\begin{array}{c}0-5 \mathrm{~cm} \\
20-25 \mathrm{~cm}\end{array}$ & 150 & $\begin{array}{l}\text { Density separation by } \\
\mathrm{NaCl}\end{array}$ & $\begin{array}{l}\text { Stereo } \\
\text { microscope, } \\
\text { ATR-FTIR }\end{array}$ & $\begin{array}{c}\mathrm{MP} \\
\text { items } / \mathrm{m}^{2}\end{array}$ & $\begin{array}{l}\text { Present } \\
\text { study }\end{array}$ \\
\hline
\end{tabular}


Despite the importance of soil MP in the food chain and public health, authors are not aware of any legislation on monitoring soil MPs, and since there is no internationally established assessments for health risks and safe quantities, MPs produced from the breakdown of everyday plastic products are likely entering the human body via the food chain [34]. It is therefore important to better understand the routes by which MPs access the terrestrial ecosystem and to explore their characterization of various categories of land use. Knowing agriculture as a significant field of Taiwanese life since ages ago and Tainan City as an important supply of agricultural goods, this study aims at quantifying and identifying MP particles in agricultural soils in Tainan City, Taiwan, and provides useful information for future MP research in terrestrial ecosystems.

\section{Materials and Methods}

\subsection{Study Area}

The study area is selected as farmlands in Tainan City, Guiren District (Figure 1). Five farmlands were selected based on their location and type of farming activities, with areas ranging from 177 to $3054 \mathrm{~m}^{2}$ (Table 2).

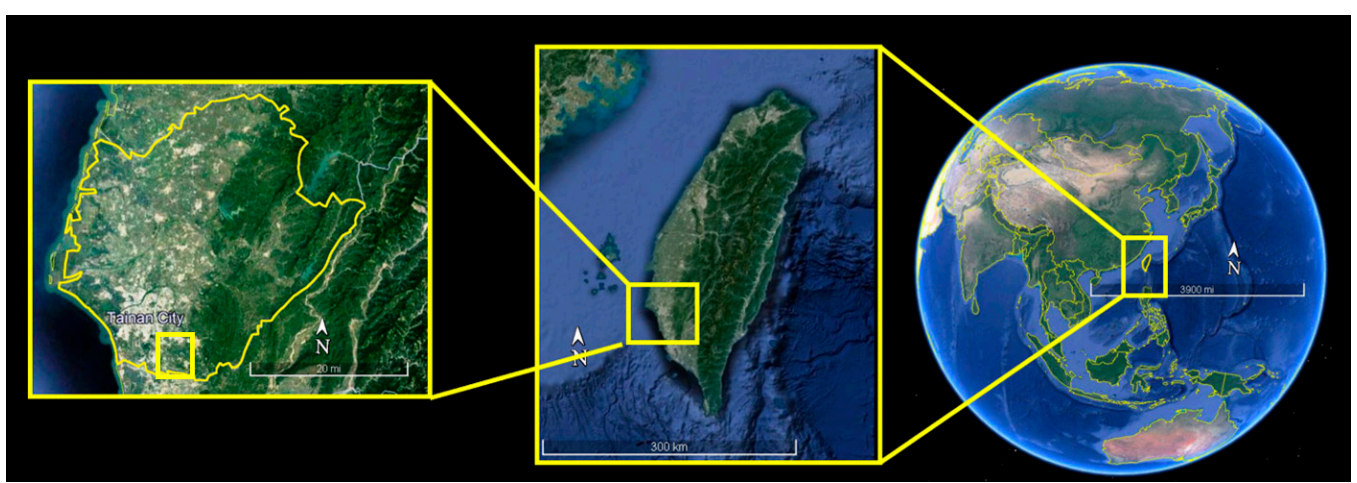

(a)

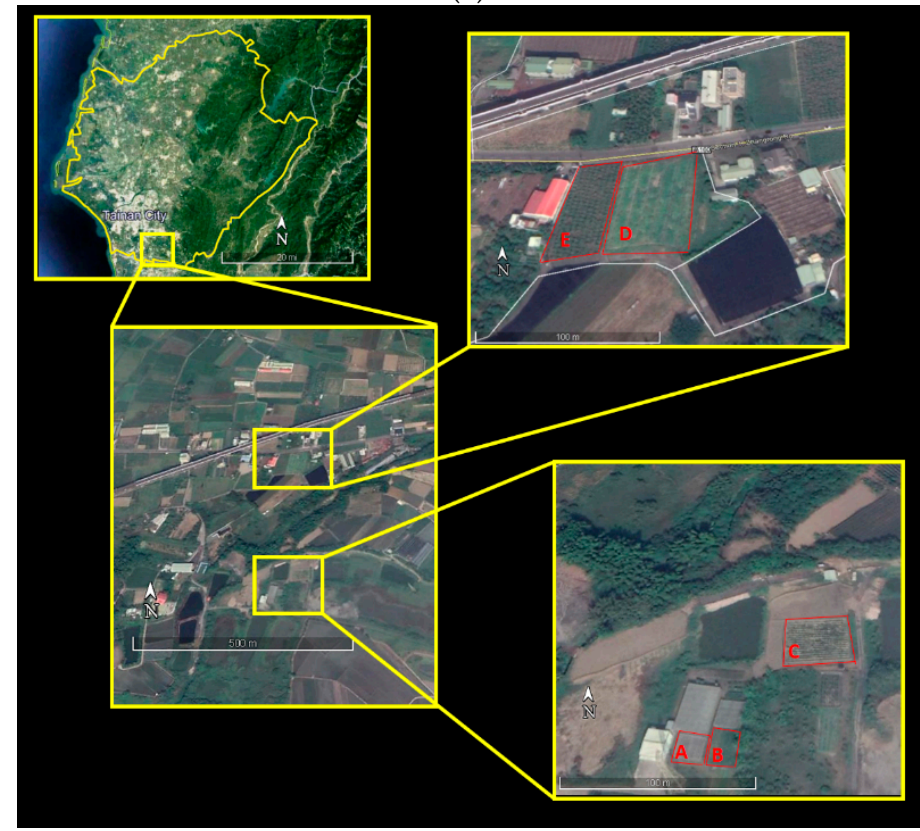

(b)

Figure 1. Location of study area: (a) Tainan City, Guiren district, and (b) farmlands in the present study (A, B, C, D, and E) (Google Earth Pro 7.3.3.7786 (2021)). 
Table 2. Farmlands characteristics in the study area.

\begin{tabular}{|c|c|c|c|c|c|c|}
\hline Farm Name & $\begin{array}{l}\text { Location Status } \\
\text { (Coordinates) }\end{array}$ & Area $\left(m^{2}\right)$ & Soil Texture & $\mathrm{pH}$ & Color & Characteristics \\
\hline A & $\begin{array}{l}\text { Road-away } \\
(22.906090, \\
120.280355)\end{array}$ & 177 & Clay & 6.5 & Olive gray & $\begin{array}{c}\text { Greenhouse, cultivated } \\
\text { with cabbage, organic } \\
\text { farming with organic } \\
\text { fertilizer }\end{array}$ \\
\hline B & $\begin{array}{l}\text { Road-away } \\
(22.906119, \\
120.280534)\end{array}$ & 275 & Clay & 6.5 & Pale olive & $\begin{array}{l}\text { Open space, harvested } \\
\text { from corn, applying } \\
\text { organic fertilizer }\end{array}$ \\
\hline C & $\begin{array}{l}\text { Road-away } \\
(22.906679, \\
120.280993)\end{array}$ & 1102 & Silt-loam & 6.5 & $\begin{array}{l}\text { Reddish- } \\
\text { brown }\end{array}$ & $\begin{array}{l}\text { Open space but fenced } \\
\text { around, cultivated with } \\
\text { asparagus, applying } \\
\text { organic fertilizer }\end{array}$ \\
\hline $\mathrm{D}$ & $\begin{array}{l}\text { Roadside } \\
(22.909624, \\
120.280480)\end{array}$ & 3054 & Silt-clay-loam & 6.5 & $\begin{array}{l}\text { Light } \\
\text { Yellowish } \\
\text { Brown }\end{array}$ & $\begin{array}{l}\text { Open space, close to a } \\
\text { residential area, } \\
\text { cultivated with } \\
\text { pumpkin, covered with } \\
\text { mulch }\end{array}$ \\
\hline E & $\begin{array}{l}\text { Roadside } \\
(22.909573, \\
120.280058)\end{array}$ & 1997 & Clay-loam & 6.5 & $\begin{array}{l}\text { Light } \\
\text { Yellowish } \\
\text { Brown }\end{array}$ & $\begin{array}{l}\text { Open space, close to a } \\
\text { residential area, } \\
\text { cultivated with guava, } \\
\text { fruits covered with } \\
\text { protective foam }\end{array}$ \\
\hline
\end{tabular}

\subsection{Sampling Strategy}

For the sampling phase, each farm was subdivided into three parts (subplots), and for each subplot, one composite sample was achieved. Each composite sample was obtained from five evenly distributed subsamples taken using a $32 \times 32 \mathrm{~cm}$ wooden quadrate frame in different soil depths (upper $5 \mathrm{~cm}$ and lower $20 \mathrm{~cm}$ ). Totally, 150 soil samples were collected for different soil depths from all farmlands.

Soil samples were then transferred into aluminum sampling bags using a metal spatula. Soil $\mathrm{pH}$ and color were determined onsite using a portable $\mathrm{pH}$ meter and Munsell color charts hue, respectively. Samples were then transferred to the laboratory for the next step of analysis, where soil sample drying was the initial step for MP analysis. Before any further sample processing, soil samples were adequately homogenized manually, followed by air drying at room temperature for about $48 \mathrm{~h}$. Soil texture was determined using the method modified by Ritchey et al. [35] and Thien [36] to get the general proportion of sand, silt, and clay in the soil samples.

\subsection{MP Extraction}

Once in the laboratory, homogenization dried samples were sieved using stainlesssteel meshes with pore sizes of 1 and $5 \mathrm{~mm}$ in commercially available test sieves to remove the large particles (i.e., $>5 \mathrm{~mm}$ ). To prevent additional plastic exposure, no plastic tools or containers were used for sampling or laboratory work.

Density separation was then used to isolate MP particles [6]. Plastic particles float on the surface of the solution as soil samples are decanted into high-density solutions, but the more dense soil materials remain at the bottom of the solution. In this procedure, soil samples were mixed with saturated $\mathrm{NaCl}$ solution in a glass beaker where samples were magnetically stirred for $15 \mathrm{~min}$. After $2 \mathrm{~h}$ of settlement, the MPs floating in the supernatant of the glass beaker were carefully removed from surface of the mixture by decanting followed by filtration through a glass microfiber filter (diameter $47 \mathrm{~mm}$, pore size $1 \mu \mathrm{m}$ ) with a vacuum pump.

Moreover, an additional step of organic matter removal was used to separate MPs from organic-rich soils, which are typical in agricultural farmlands. Different oxidizing agents are able to remove organic matters from environmental matrices [37]. Fenton's 
reagent is considered as an advanced oxidation process using hydrogen peroxide $\left(\mathrm{H}_{2} \mathrm{O}_{2}\right)$ in the presence of a catalyst $\left(\mathrm{Fe}^{2+}\right)$. However, since the Fenton reaction is $\mathrm{pH}$ sensitive, an iron hydroxide precipitate will form if the $\mathrm{pH}$ increases above 5-6. Due to physical obscuration, this precipitate floats out during density separation, preventing visual inspection and chemical characterization. Furthermore, the acidity condition may cause certain polymers to degrade, affecting the calculation of total MPs. Moreover, Corradini et al. [28] found that the recovery of nylon and acrylic fibers was significantly reduced when Fenton's reagent method was used. Therefore $\mathrm{H}_{2} \mathrm{O}_{2}$ was used as an oxidizing agent in the current study as overnight or $24 \mathrm{~h}$ treatment with only $30 \%$ or $35 \% \mathrm{H}_{2} \mathrm{O}_{2}$ was found not to affect plastic particles [37].

Soil samples were thus treated with $30 \% \mathrm{H}_{2} \mathrm{O}_{2}$ overnight to remove natural organic material, followed by filtration and a second drying step. Filter papers were then saved in Petri dishes for further inspection and identification. A schematic diagram of analytical procedures for MPs extraction in soil samples is depicted in Figure 2.

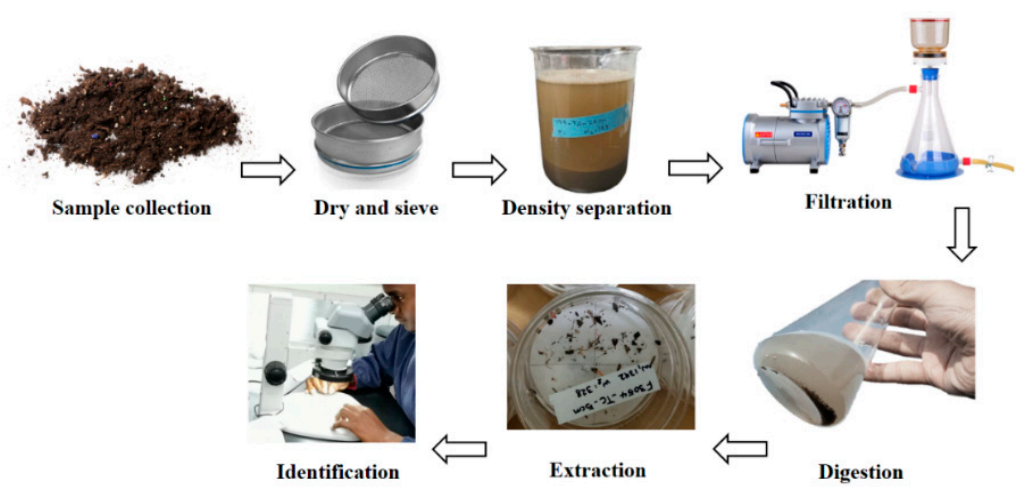

Figure 2. Schematic diagram in analytical procedures for MPs extraction in soil samples.

\subsection{MP Identification and Characterization}

The size, type, and color of MPs can be used to classify them. Under a magnifying lamp, MP samples were optically sorted and quantified, and then examined under a stereomicroscope (model SMZ 745 T coupled with a NI-150 high-intensity illuminator, Nikon, Tokyo, Japan) where the MP particles collected on each filter were counted twice. It was considered that MP particles had polished textures, bright colors, and sharp geometrical shapes. Synthetic fibers were known to have smooth sides and solid colors, as pointed out by Horton et al. [7]. Particles were classified according to their shapes: fibers, fragments (angular and solid), films (flexible and thin), foams (white and spongy), pellets (disc- or lentil-shaped), or microbeads (rounded and solid).

To identify the polymer composition of MPs, 42 items were picked up to be further analyzed by a Fourier transform infrared (FTIR) spectrometer (Model Spectrum One, Perkin Elmer) equipped with a platinum ATR single reflection diamond crystal-based module in the mid IR range (525-4000 $\mathrm{cm}^{-1}$ ). Sixteen scans and $4 \mathrm{~cm}^{-1}$ resolution were applied and the obtained spectrums were compared with the standard database.

\subsection{Statistical Analysis}

MPs were investigated according to color, size, composition, and type. The abundance of MPs in the soil samples was expressed as particles $/ \mathrm{m}^{2}$. The data are shown as mean \pm standard deviation and were recorded and drawn using Microsoft Excel 2016 and SPSS 18.0 software package. The data were subjected to analysis of variance, sample $t$-test, and one-way ANOVA where differences at $p<0.05$ were considered to be statistically significant. 


\subsection{Quality Assurance (QA) and Quality Control (QC)}

MP separation and extraction was carried out in a laboratory with no cross-contamina tion. To prevent false interpretation, all experiments were performed with deionized water and dustproof clothes. Since a site with zero plastic exposure could not be guaranteed, and there is no standard procedure for MP sampling technique in soil ecosystems, two methods were used for taking control samples. First, the US Department of Agriculture [38] and the US Environmental Protection Agency [39] sampling recommendations were adopted, which proposed taking control samples of the same soil type from a nearby region that was not contaminated by the contaminant of concern. While this could be difficult for MPs that are ubiquitously deposited in soil [40], it allowed for the quantification of MP background levels, the monitoring of contaminants added during sampling, and a greater understanding of matrix interferences. To comply with this approach, the control samples of the current study were first obtained from farm " $\mathrm{A}$ " and the location that meets the criteria of being far from the road, mulch free, protection foam-free, and fenced the surrounding. Although not completely free of plastics, the control site had the lowest MP count, where results were corrected by subtracting background values. Alternatively, another set of control samples without plastic particles was artificially made based on Corradini et al. [28] to check whether the transportation and handling polluted the samples with plastic, influencing the quality of the analysis. To ensure the removal of all plastic particles, agricultural soil samples were collected from each farm, dried, sieved, and ignited at $500{ }^{\circ} \mathrm{C}$ for $3 \mathrm{~h} \mathrm{[41]}$. To simulate sample transportation to the laboratory, three replicates $(450 \mathrm{~g}$ ) of the ignited soil were placed in aluminum bags (same as experimental samples) and shaken at $120 \mathrm{rpm}$ for $20 \mathrm{~min}$ in an orbital shaker. After that, the samples were unpacked and tested in the same manner as other samples. The risk of contamination was minimized by using non-plastic sampling tools and containers, as well as avoiding the use of plastic shovels or nitrile gloves.

A recovery experiment was set up using triplicates based on the procedures described in Section 2.3. Six soil samples were spiked with 15 particles between 1 and $5 \mathrm{~mm}$, including five black fragment, five white foams, and five fibers. The average recoveries ranged from 85 to $95 \%$, with fibers giving the lowest recoveries.

\section{Results and Discussion}

\subsection{Abundance and Distribution of MPs}

Agricultural farmlands in southern Tainan City with an area range of 0.01 to 0.3 ha (Figure 1b) served as the study site (Table 2).

MPs were found in all soil samples in different depths ranging from $12-117$ items $/ \mathrm{m}^{2}$, with the mean concentration of 53.2 and 34.6 items $/ \mathrm{m}^{2}$ in 5 and $20 \mathrm{~cm}$ depths, respectively (Table 3 and Figure 3). Sampling site E and A were found with the highest and lowest average MPs concentrations, respectively, with a difference of almost five magnitudes $(p$-value $=0.028)$.

Table 3. Statistics of MPs abundance for different sample types.

\begin{tabular}{|c|c|c|c|c|c|}
\hline Sample Type & Sample Site & $\begin{array}{c}\text { Abundance } \\
\left(\text { Items } / \mathrm{m}^{2}\right)\end{array}$ & $\begin{array}{c}\text { Average } \\
\left(\text { Items } / \mathrm{m}^{2}\right)\end{array}$ & $\mathrm{SD} *$ & $\mathbf{C V} * *$ \\
\hline \multirow[t]{5}{*}{ Upper soil (top $5 \mathrm{~cm}$ ) } & A & 26 & \multirow[t]{5}{*}{53.2} & \multirow[t]{5}{*}{34.8} & \multirow[t]{5}{*}{0.65} \\
\hline & B & 43 & & & \\
\hline & $\mathrm{C}$ & 20 & & & \\
\hline & D & 60 & & & \\
\hline & $\mathrm{E}$ & 117 & & & \\
\hline \multirow[t]{5}{*}{ Lower Soil (deep $20 \mathrm{~cm}$ ) } & A & 12 & \multirow[t]{5}{*}{34.6} & \multirow[t]{5}{*}{20.3} & \multirow[t]{5}{*}{0.58} \\
\hline & B & 23 & & & \\
\hline & $\mathrm{C}$ & 22 & & & \\
\hline & D & 49 & & & \\
\hline & $\mathrm{E}$ & 67 & & & \\
\hline
\end{tabular}

* SD: standard deviation; ${ }^{* *} \mathrm{CV}$ : coefficient of variation. 


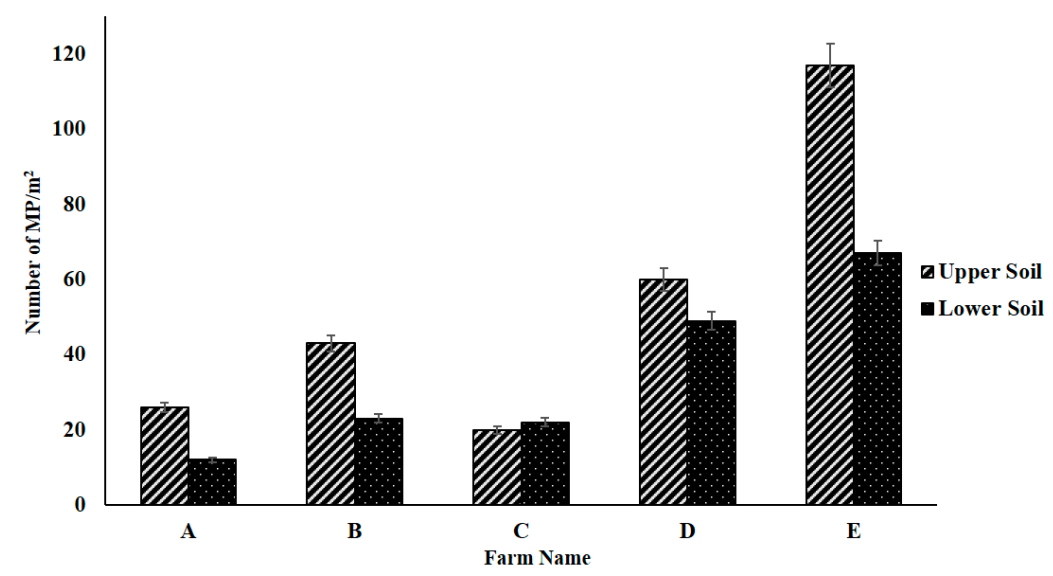

Figure 3. MPs abundance in farmlands under the study at different depths.

The high concentration of MPs in Farm E can be attributed to its special characteristics as it was adjacent to the suburban roads planted with guava where most of the fruits were fully covered with protective foams and a plastic wrap, which are easily fragmented and carried off by wind and human activities, become brittle when exposed to UV rays in sunlight, and are burrowed into the soil media resulting in farmlands pollution (Table 2 and Figure 4).

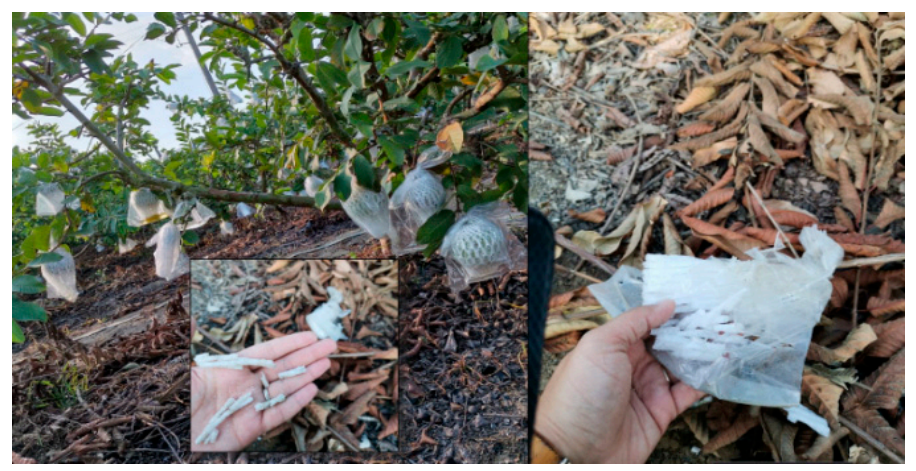

Figure 4. Fruit packing EPE foam net and plastic cover used for the package for the fruits in farm E.

On the other hand, farm A, is an enclosed greenhouse apart from suburban road planting with cabbage which needs regular monitoring and managed practice.

Around suburban roads and residential districts, there are numerous sources of MPs emissions. Tire tread particles, in addition to plastic debris from buildings and residential areas, have recently been identified as an environmental source of MPs. They are scattered through the environment as a result of the frictional interface between the tire and the road surface [42]. Chen et al. [32] also proved that the mean abundance of MPs levels is higher in areas adjacent to the suburban roads than those are far from the roadside.

Besides, $t$-test analysis results showed no statistically significant difference between mean MPs particles in two different depths $(p$-value $=0.383)$. As shown in Figure 3, there was as high as 67 items $/ \mathrm{m}^{2}$ in deep soil samples, which shows MPs have been detected in various soil profiles, likely as a result of movement through cracks, fissures, and biopores, including earthworm burrows and root channels [43].

\section{2. $M P^{\prime}$ 's Size Distribution}

Generally, MPs of $1-3 \mathrm{~mm}$ and $>5 \mathrm{~mm}$ accounted for the largest and smallest proportions of all soil samples MPs, respectively (Figure 5a). The average proportions of MPs was $2.56 \mathrm{~mm}$ and $1.43 \mathrm{~mm}$ in upper and lower soil layers, respectively (Figure $5 \mathrm{~b}$ ) where farms 
$\mathrm{D}$ and $\mathrm{E}$ showed an overall larger size of MPs. Unlike the insignificant difference in distribution and availability of MPs in different soil depths (Section 3.1), deeper soil samples contained significantly smaller size of MPs compared with surface soil ( $p$-value $=0.011$ ). These MPs with small particle sizes are easily ingested by organisms and may enter higher trophic levels in the food web [44].

(a)

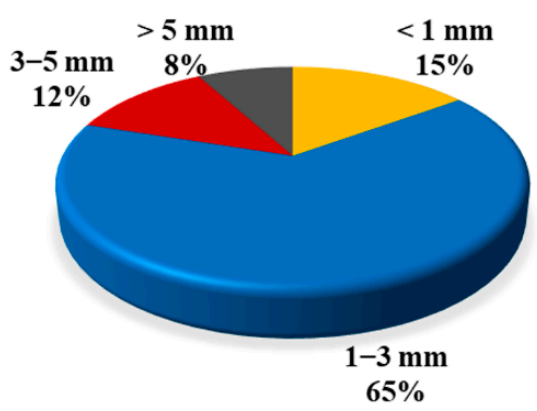

(b)

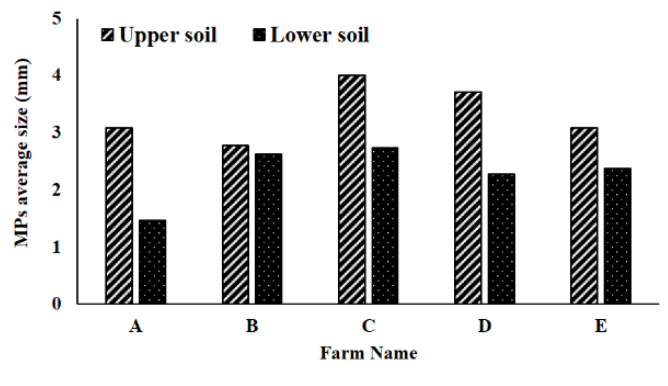

Figure 5. Size distribution of MPs in (a) all soil samples, and (b) in different farms under different depth.

Farm D was extensively covered with plastic mulch (Table 2 and Figure 6), and Plastic mulching is suspected to be a major source of MPs in farmland soil, since the mulch is often left on the fields after harvesting, resulting in hotspots of plastic waste [45]. As a result of photolytic, mechanical, and biological degradation, large quantities of (micro-) plastics are buried in topsoil and plowed soil [46], and most of the plastic mulch broken into smaller parts (5 mm, i.e., MPs) becomes an MP pollutant $[47,48]$.

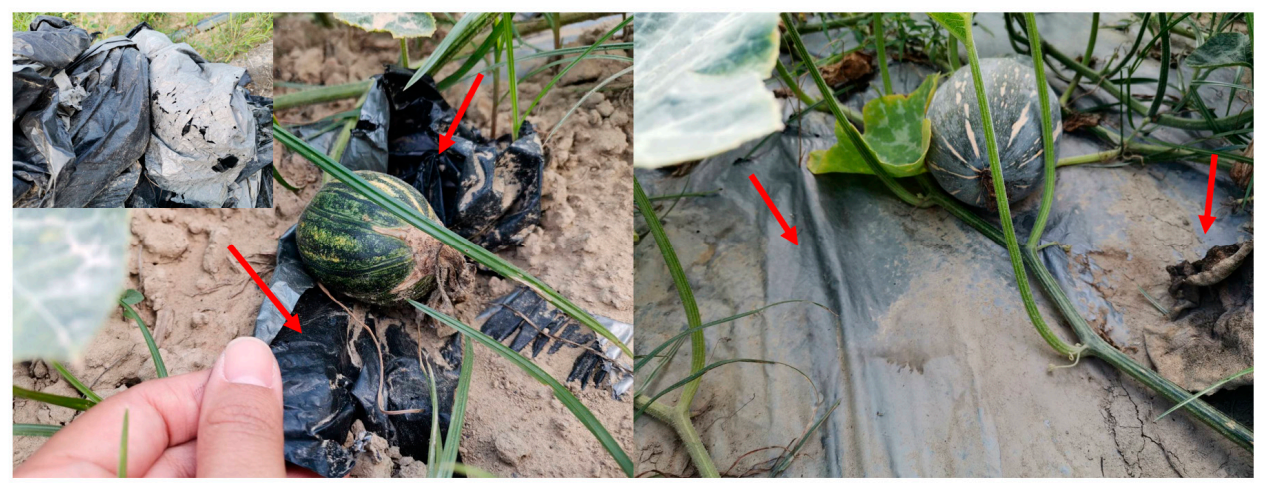

Figure 6. Extensive application of plastic mulch in farm D, cultivated by pumpkin.

The size of MP particles has been shown to have an effect on soil organisms. MPs in soils can be consumed [49] or transported to other soil organisms [50,51], resulting in adverse physiological effects [52]. Rillig et al. [53], for example, investigated how the earthworm transports MPs of different sizes. While different MP particles were found in the middle and bottom layers of the soil after exposure to MPs, and small size particles were found in the lowest soil layer. MPs impacted the growth, survival, reproduction, and immune system of the worm Eisenia andrei, according to Rodriguez-Seijo et al. [54]. Organic contaminants, such as chemical additives and hydrophobic chemical molecules, are also carried by MPs [55]. MPs with a particle size of less than $1 \mathrm{~mm}$, can be thus extremely detrimental to local soil species and the agricultural ecosystem.

There was no significant difference in the size distribution of MPs between farms adjacent to suburban roads and road-away farms $(p$-value $=0.281)$, indicating that the size distribution of MP particles is irrelevant to the locations of sampling sites. This is in line with Chen et al. [32], who studied MP emissions in vegetable farmlands in the suburbs 
of Wuhan, China, and found that environmental conditions were the primary cause of chemical changes in plastics, which made them more brittle and eventually led to the accumulation of small-sized MPs in the soil.

\subsection{MP's Shape and Identification}

The MPs were classified into six categories based on their characteristics and morphology, namely fibers (elongated strings), pellets (disc- or lentil-shaped), films (soft transparent flakes), fragments (hard angular pieces), foams (White and spongy, often spherical), and (f) microbeads (Small, solid, manufactured plastic particles) (Figure 7). The various sources of plastic waste surrounding the sample sites could explain the heterogeneity of the dominant shapes of MPs in each site. In total, fragments and fibers were the dominated shapes of MPs, accounting for $43 \%$ and $21 \%$ respectively, followed by the foams (16\%), films (13\%), pellets $(6 \%)$, microbeads $(0.6 \%)$, and others $(0.4 \%)$ (Figure 8 ).

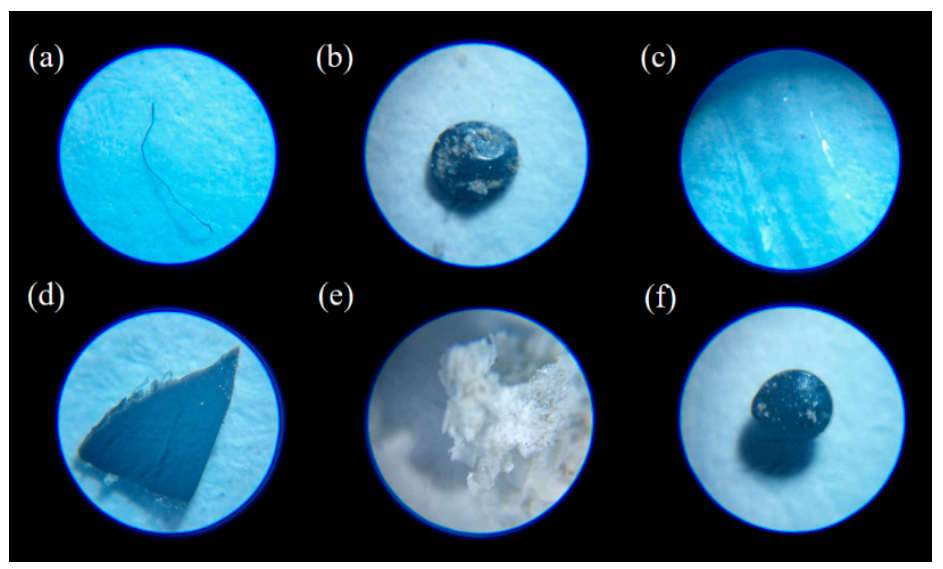

Figure 7. Different shape of MPs detected in this study including (a) fibers, (b) pellets, (c) films, (d) fragments, (e) foams, and (f) microbeads.

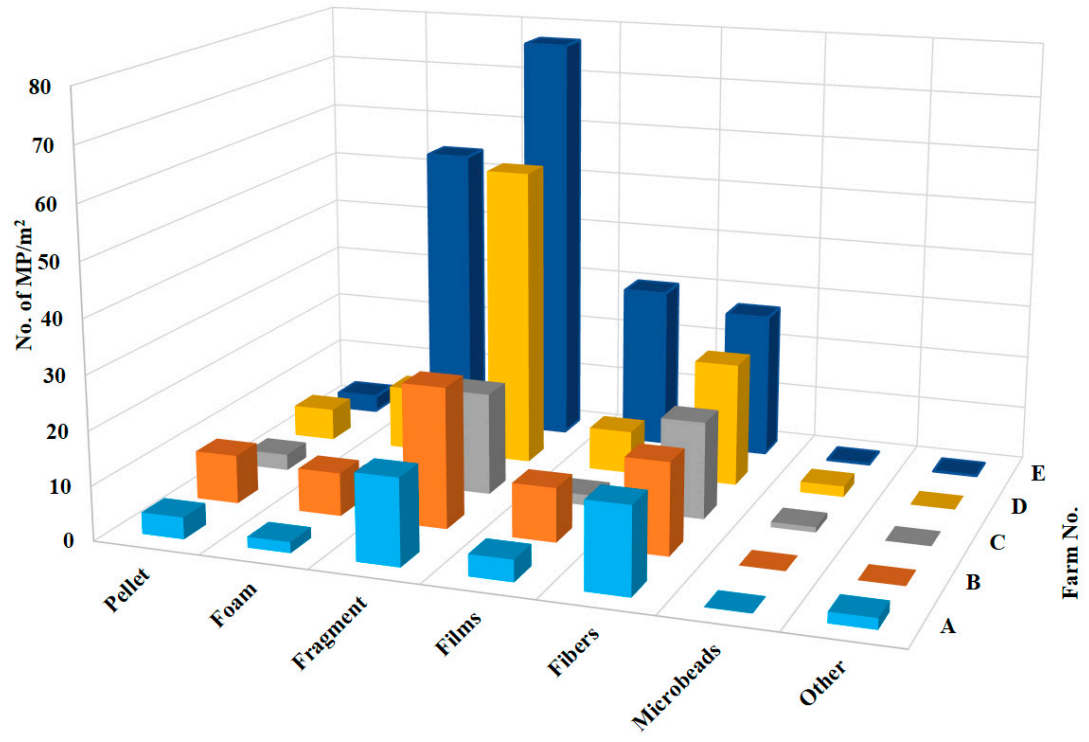

Type of MP

Figure 8. Type distribution of MPs detected in the studied farmlands.

While the one-way ANOVA test indicated that there is a significant difference between number of MPs in different farmlands ( $p$-value $=0.042)$, first three farms $(A, B$, and C) showed similar range of microfiber items in soil samples where other types were in different 
proportions. If control and remediation efforts are to be successful, it is important to consider the origins and distribution of microfibers in the environment.

While primary causes are yet to be thoroughly studied, domestic laundry discharges were once thought to be the main source of fibrous MPs. Recent research, however, contradicts this assertion [56,57]. A recent study has revealed that the estimate for fibers in the aquatic environments was disproportionately higher than were the concentrations found in wastewater effluent [58]. Microfibers are found in a diverse variety of species across various ecosystems and trophic layers, including those targeted by fisheries, according to several field studies [59], which highlights the significance of exposure to MPs through the fishery and aquaculture industries.

Interestingly, using historical images from Google Erath, farms A, B, and C in the current study were found to be fish farms back in past years (Figure 9) where microfibers could possibly derive from ropes and fishing nets as commonly used accessories in aquaculture practices. This may also confirm the long life of MPs products in the terrestrial environment even after changing the land use category. Furthermore, commonly used agricultural plastic products like shade nets and fertilizer bags can decompose into fibers over time in the environment.
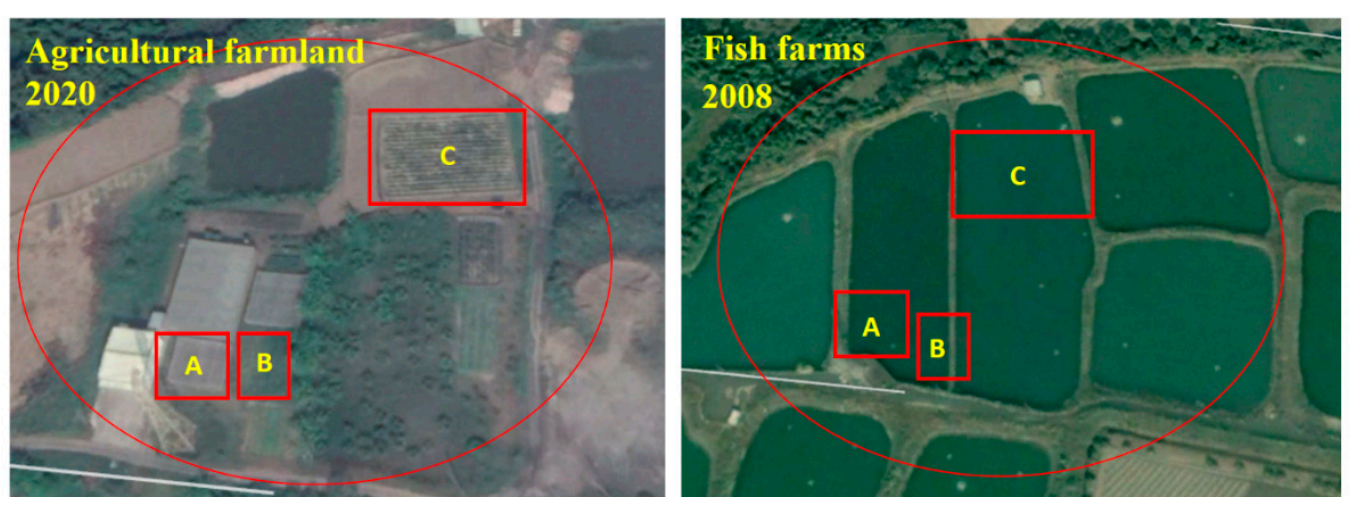

Figure 9. Historical land use image comparison of first three farms (A, B, and C) in this study (Google Earth Pro 7.3.3.7786 (2021)).

Among various forms of detected MPs in this study, foams followed by fragments and films were significantly ( $p$-value $<0.001$ ) higher in farms D, and E compared with the other ones. The statistical analysis showed that the number of fragments and foams in farm $\mathrm{E}$ were significantly higher than the average number of these items in all farms under the study with $p$-values of 0.032 and 0.017 , respectively. Although not statistically significant at $95 \%$ confidence interval, but the number of fragments in farm $\mathrm{D}$ was also higher than other farms. This can be well attributed to the field observations where farm $\mathrm{D}$ was fully covered with plastic mulch and planted fruits in farm E were covered with protective foam and plastic wrap (Table 2, and Figures 4 and 6). Since these two farms were adjacent (Figure 1b), MPs could be easily carried off between the farms by natural wind and/or human activities.

MPs were observed in different colors, and no significant correlation has been found between MP color and type ( $p$-value $=0.09$ ). However, black and white were the dominant colors for the fragments and foams in farms $\mathrm{D}$ and $\mathrm{E}$, respectively, possibly due to the black plastic much in farm $D$ and white protective foam in farm $E$ (Figures 4 and 6). Although no significant correlation was also found between soil color, texture, and MP distribution ( $p$-value $>0.05$ ), this remains to be further studied by collecting more samples from different soil types in future as soil parameters such as texture and organic matter content could be potential driver for MP size distribution. 


\subsection{MP Identification}

The ATR-FTIR comparative spectra of MPs extracted from the various soil samples were plotted as shown in Figure 10. Five plastic debris categories, including PE, LDPE, oxidized polyethylene (oxidized PE) polypropylene (PP), and PS were identified, with a mean match degree of $85.67 \%$ with the standard database. The match degrees of the three PE categories were relatively higher than PS, which is consistent with Fok et al. [60] reporting that the match degrees of PS forms are lower than PP and PE. Weathering, aging, and adherence can all have an impact on the matching degree of MPs with the standard database. Statistical results indicate that LDPE followed by PS are the major polymer type of MPs in the studied farms, which is in consistent with the main type of MP found in the study, fragment and fibers.

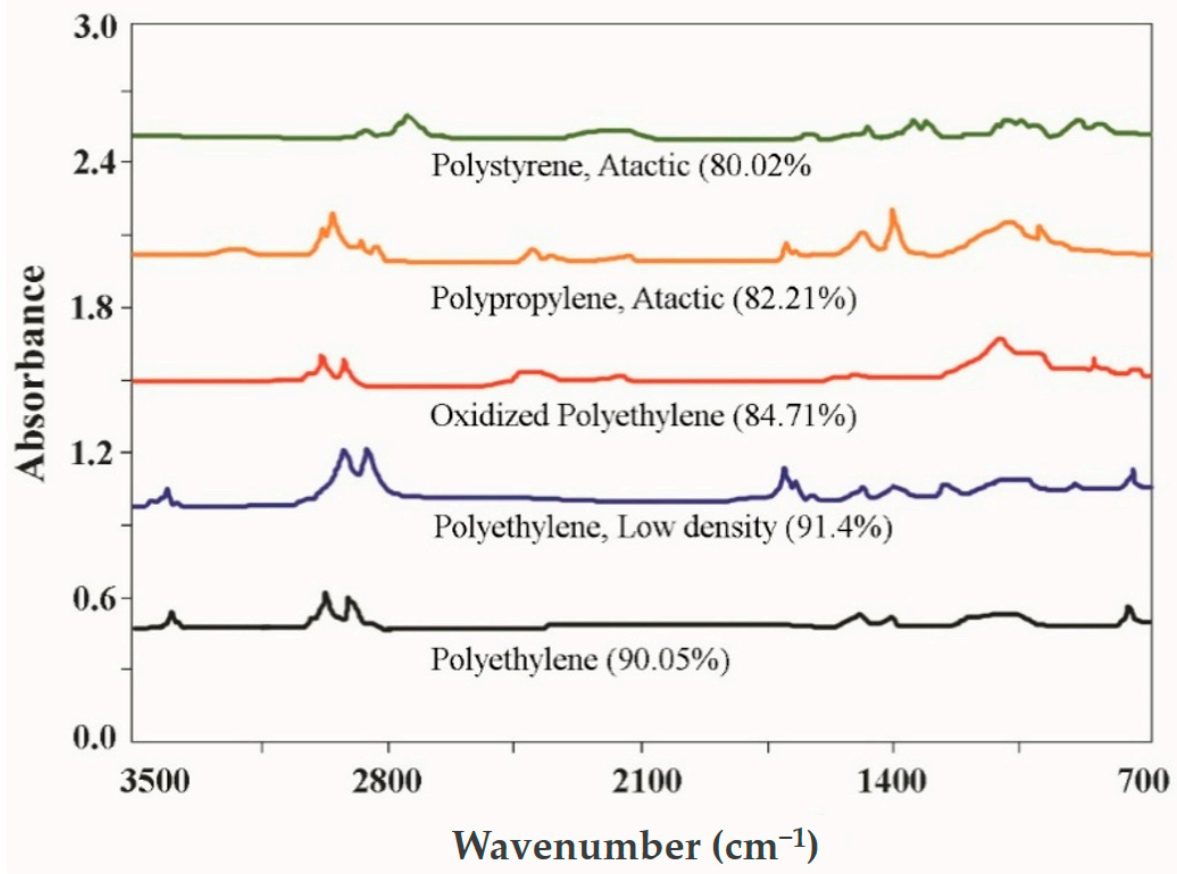

Figure 10. The FTIR spectrum of selected MPs detected in soil samples and the match degrees with the standard spectrum.

The presence of hydroxyl and carbonyl absorption peaks in the samples, which are about 3450 and $1700 \mathrm{~cm}^{-1}$, means that the MPs surface produces functional groups including carboxyl, aldehyde, and hydroxyl [61]. MPs can thus serve as carriers for adsorbing pollutants, making it easier to pass contaminants and threatening ecosystems [62], moreover, degraded MPs also release more harmful additives into the environment [63].

\subsection{Challenges and Limitation}

Scientists have been increasingly interested in researching MP pollution in terrestrial environments in recent years. However, there are no reports that characterize the problem across different land use settings, and the true extent of the problem is yet to be determined. While our results highlighted the role of agricultural activities in MP pollution, there are several potential methodological issues that need to be considered for future studies. Representative sampling is one of the most important steps during MP analysis in soil ecosystems. In MP monitoring and analysis, the sampling method must be very carefully designed in order to achieve reliable outcomes when working with such an inhomogeneous matrix as soil. It is highly recommended to consider the sampling location's historical use, potential discharge from point sources (e.g., containers, picnic areas, etc.) or diffuse sources (e.g., local highways, lanes, and even traffic rates). Taking control samples to verify the accuracy of the analysis is another obstacle because it is almost difficult to guarantee 
a site free of plastic contaminants, and there is no standard protocol for MP sampling in soil media. Removing all possible plastic particles from a collected sample through hightemperature ignition [28] or taking control samples from nearby soil with the lowest plastic contamination [38,39], have been suggested to make a plastic-free control sample, but either of these methods have their own limitations and drawbacks and may not provide a fully representative control sample for MP analysis in a terrestrial environment. Pre-treatment of samples, such as drying and sieving conditions, as well as organic matter removal, is another important step that the research team should carefully consider. While various oxidizing agents, such as $\mathrm{H}_{2} \mathrm{O}_{2}$ or Fenton's reagent solution, have been developed for organic matter removal, acidity conditions or oxidizing strength can reduce the recovery of some plastic products and microfibers [28]. Visual inspection is dependent on the operator's strategy, so MP identification is another challenging task. To prevent false positives, additional detection methods are recommended. However, combining visual and other advanced techniques, such as spectroscopic methods, can also significantly increases the cost and complexity of the research, and it may not be possible with all samples in the study [28].

In the present study, it was found that for interpreting MP sources, it is necessary to conduct an integrated site assessment and collect historical data on land use with its different practices on the study area as MPs may remain in the soil decades after the emission from the source.

\section{Conclusions}

The aim of this study was to reveal MPs contamination in farmland soil. Due to the use of different sampling, extraction, and analytical approaches, research on MPs in soils is still scarce, and the existing publications are also incomparable. The studied farmlands in Tainan City, Taiwan were extensively contaminated by MPs. The concentration of MPs in roadside farms was higher than in enclosed farms away from suburban roads, suggesting a possible risk of agricultural activities on the side of the road. For the MPs described, micro-fragment and -fibers were the most common types, with LDPE being the dominated polymer type. Generally, mulching practice, historical fish farming activity, protective foams, and roadside farming were found to be the main sources of MPs present in the current study. Despite the fact that MPs in the environment may have harmful effects on soil and organisms, the prevalence of MPs in soil and the terrestrial environment is expected to continue to grow in the immediate future, as their occurrence in soil ecosystems is largely unknown. Improving the biodegradability of polymers used in the production of plastic mulch and synthetic textiles may aid in the reduction of MPs in the environment. Since simple precautionary measures in agricultural practices, such as farm fencing or removing left-over plastic residues after harvesting can potentially reduce MPs pollution in farmland, raising awareness among farmers might help to slow down the MP waste generation and encourage the utility of more natural fibers and environmentally friendly products in agriculture practices.

Author Contributions: Conceptualization, H.F.; data curation, H.F. and M.I.; formal analysis, H.F.; investigation, N.T.Y., A.M.M., N.N.L., F.B.M., P.C.J., N.S.J., B.H.M., and J.T.M.; methodology, N.T.Y., A.M.M., N.N.L., F.B.M., P.C.J., N.S.J., B.H.M., and J.T.M.; software, N.T.Y.; supervision, S.-L.L.; validation, S.-L.L.; writing-review and editing, M.I. All authors have read and agreed to the published version of the manuscript.

Funding: This research was funded by the Ministry of Science and Technology of Taiwan (MOST), with grant number MOST 108-2621-M-309 -001 -MY2. This work was also partially supported by the by National Taiwan University (NTUCCP-109L901003, NTU-109L8836), and NTU Research Center for Future Earth from The Featured Areas Research Center Program within the framework of the Higher Education Sprout Project by the Ministry of Education (MOE) in Taiwan, and the Ministry of Science and Technology of Taiwan (MOST108-2621-M-002-MY2). 
Data Availability Statement: The data that support the findings of this study are available from the corresponding author upon reasonable request.

Acknowledgments: The authors gratefully acknowledge the Social Responsibility (USR) office of the Chang Jung Christian University and Eco Center for administrative and technical support.

Conflicts of Interest: The authors declare no conflict of interest.

\section{References}

1. Geyer, R.; Jambeck, J.R.; Law, K.L. Production, use, and fate of all plastics ever made. Sci. Adv. 2017, 3, e1700782. [CrossRef]

2. Wright, S.L.; Kelly, F.J. Plastic and human health: A micro issue? Environ. Sci. Technol. 2017, 51, 6634-6647. [CrossRef] [PubMed]

3. Gewert, B.; Plassmann, M.M.; MacLeod, M. Pathways for degradation of plastic polymers floating in the marine environment. Environ. Sci: Process Impacts 2015, 17, 1513-1521. [CrossRef] [PubMed]

4. Kunz, A.; Walther, B.A.; Löwemark, L.; Lee, Y.C. Distribution and quantity of microplastic on sandy beaches along the northern coast of Taiwan. Mar. Pollut. Bull. 2016, 111, 126-135. [CrossRef] [PubMed]

5. Frias, J.P.G.L.; Nash, R. Microplastics: Finding a consensus on the definition. Mar. Pollut. Bull. 2019, 138, 145-147. [CrossRef]

6. Liu, M.; Lu, S.; Song, Y.; Lei, L.; Hu, J.; Lv, W.; Zhou, W.; Cao, C.; Shi, H.; Yang, X.; et al. Microplastic and mesoplastic pollution in farmland soils in suburbs of Shanghai, China. Environ. Pollut. 2018, 242, 855-862. [CrossRef]

7. Horton, A.A.; Walton, A.; Spurgeon, D.J.; Lahive, E.; Svendsen, C. Microplastics in freshwater and terrestrial environments: Evaluating the current understanding to identify the knowledge gaps and future research priorities. Sci. Total Environ. 2017, 586, 127-141. [CrossRef] [PubMed]

8. Kawecki, D.; Nowack, B. Polymer-Specific Modeling of the Environmental Emissions of Seven Commodity Plastics as Macroand Microplastics. Environ. Sci. Technol. 2019, 53, 9664-9676. [CrossRef]

9. Arthur, C.; Baker, J.; Bamford, H. International Research Workshop on the Occurrence, Effects, and Fate of MP Marine Debris; Technical Memorandum NOS-OR\&R-30; NOAA: Tacoma, WA, USA, 2009; p. 530.

10. Li, L.; Luo, Y.; Peijnenburg, W.J.G.M.; Li, R.; Yang, J.; Zhou, Q. Confocal measurement of microplastics uptake by plants. MethodsX 2020, 7, 100750. [CrossRef]

11. Cole, M.; Lindeque, P.; Halsband, C.; Galloway, T.S. Microplastics as contaminants in the marine environment: A review. Mar. Pollut. Bull. 2011, 62, 2588-2597. [CrossRef]

12. Shonbeck, M.W.; Evanylo, G.K. Effects of Mulches on Soil Properties and Tomato Production I. Soil Temperature, Soil Moisture and Marketable Yield. J. Sustain. Agric. 1998, 13, 55-81. [CrossRef]

13. Kasirajan, S.; Ngouajio, M. Polyethylene and biodegradable mulches for agricultural applications: A review. Agron. Sustain. Dev. 2012, 32, 501-529. [CrossRef]

14. Waggoner, P.E.; Miller, P.M.; De Roo, H. Plastic mulching: Principles and benefits. Conn. Agric. Expt. Station. Bull. 1960, $634,44$.

15. Shah, F.; $\mathrm{Wu}, \mathrm{W}$. Chapter Five-Use of plastic mulch in agriculture and strategies to mitigate the associated environmental concerns. Adv. Agron. 2020, 164, 231-287.

16. Lambert, S.; Wagner, M. Environmental performance of bio-based and biodegradable plastics: The road ahead. Chem. Soc. Rev. 2017, 46, 6855-6871. [CrossRef]

17. United Nations Environmental Program (UNEP). Marine Plastic Debris and Microplastics: Global Lessons and Research to Inspire Action and Guide Policy Change; UNEP: Nairobi, Kenya, 2016; pp. 1-274.

18. Wang, J.; Liu, X.; Li, Y.; Powell, T.; Wang, X.; Wang, G.; Zhang, P. Microplastics as contaminants in the soil environment: A mini-review. Sci. Total Environ. 2019, 691, 848-857. [CrossRef]

19. Wiesner, Y.K.; Müller, A.; Bannick, C.G.; Bednarz, M.; Braun, U. Pathways of microplastics in soils-Detection of microplastic contents in compost using a thermal decomposition method. In Proceedings of the 22nd EGU General Assembly, Vienna, Austria, 4-8 May 2020; EGU2020-22456. [CrossRef]

20. Simon, N.; Schulte, M.L. Stopping Global Plastic Pollution: The Case for an International Convention; Heinrich-Böll-Foundation: Berlin, Germany, 2017; Volume 43, pp. 1-56.

21. Giuffrè, A.M.; Louadj, L.; Rizzo, P.; De Salvo, E.; Sicari, V. The Influence of Film and Storage on the Phenolic and Antioxidant Properties of Red Raspberries (Rubus idaeus L.) cv. Erika. Antioxidants 2019, 8, 254. [CrossRef] [PubMed]

22. Mills, N.J. (Report 167) Polyolefin Foams; Rapra Review Reports; iSmithers Rapra Publishing: Shropshire, UK, 2003; Volume 14, ISSN 0889-3144.

23. Khan, R.K.; Strand, M.A. Road dust and its effect on human health: A literature review. Epidemiol. Health 2018, 40, e2018013. [CrossRef] [PubMed]

24. Abbasi, S.; Keshavarzi, B.; Moore, F.; Delshab, H.; Soltani, N.; Sorooshian, A. Investigation of microrubbers, microplastics and heavy metals in street dust: A study in Bushehr city, Iran. Environ. Earth. Sci. 2017, 76, 798. [CrossRef]

25. Sommer, F.; Dietze, V.; Baum, A.; Sauer, J.; Gilge, S.; Maschowski, C.; Gieré, R. Tire Abrasion as a Major Source of Microplastics in the Environment. Aerosol Air Qual Res. 2018, 18, 2014-2028. [CrossRef]

26. Knight, L.J.; Parker-Jurd, F.N.F.; Al-Sid-Cheikh, M.; Thompson, R.C. Tyre wear particles: An abundant yet widely unreported microplastic? Environ. Sci. Pollut. Res. 2020, 27, 18345-18354. [CrossRef] 
27. Hurley, R.R.; Nizzetto, L. Fate and occurrence of micro(nano)plastics in soils: Knowledge gaps and possible risks. Curr. Opin. Environ. Sci. Health 2018, 1, 6-11. [CrossRef]

28. Corradini, F.; Meza, P.; Eguiluz, R.; Casado, F.; Huerta-Lwanga, E.; Geissen, V. Evidence of microplastic accumulation in agricultural soils from sewage sludge disposal. Sci. Total Environ. 2019, 671, 411-420. [CrossRef]

29. Beriot, N.; Peek, J.; Zornoza, R.; Geissen, V.; Huerta Lwanga, E. Low density-microplastics detected in sheep faeces and soil: A case study from the intensive vegetable farming in Southeast Spain. Sci. Total Environ. 2021, 755, 142653. [CrossRef] [PubMed]

30. Yang, J.; Li, R.; Zhou, Q.; Li, L.; Li, Y.; Tu, C.; Zhao, X.; Xiong, K.; Christie, P.; Luo, Y. Abundance and morphology of microplastics in an agricultural soil following long-term repeated application of pig manure. Environ Pollut. 2021, 272, 116028. [CrossRef] [PubMed]

31. Li, W.; Wufuer, R.; Duo, J.; Wang, S.; Luo, Y.; Zhang, D.; Pan, X. Microplastics in agricultural soils: Extraction and characterization after different periods of polythene film mulching in an arid region. Sci. Total Environ. 2020, 749, 141420. [CrossRef]

32. Chen, Y.; Leng, Y.; Liu, X.; Wang, J. Microplastic pollution in vegetable farmlands of suburb Wuhan, central China. Environ. Pollut. 2020, 257, 113449. [CrossRef]

33. Harms, I.K.; Diekötter, T.; Troegel, S.; Lenz, M. Amount, distribution and composition of large microplastics in typical agricultural soils in Northern Germany. Sci. Total Environ. 2021, 758, 143615. [CrossRef]

34. Taiwan Environmental Protection Administration. Electronic Environmental Policy Monthly; Taiwan Environmental Protection Administration: Taipei City, Taiwan, 2018; Volume XXIII, p. 12. ISSN 1811-4008.

35. Ritchey, E.L.; McGrath, J.M.; Gehring, D. Determining Soil Texture by Feel. Agric. Nat. Resour. Publ. 2015,4 , 139.

36. Thien, S.J. A flow diagram for teaching texture by feel analysis. J. Agron. Educ. 1979, 8, 54-55. [CrossRef]

37. Wang, Z.; Taylor, S.E.; Sharma, P.; Flury, M. Poor extraction efficiencies of polystyrene nano- and microplastics from biosolids and soil. PLoS ONE 2018, 13, e0208009. [CrossRef]

38. Schoeneberger, P.; Wysocki, D.; Benham, E.; Staff, S.S. Field Book for Describing and Sampling Soils; Version 3.0; Natural Resources Conservation Service; National Soil Survey Center: Lincoln, NE, USA, 2012.

39. EPA, U. LSASD Operating Procedure for Soil Sampling; Technical Report LSASDPROC-300-R4; Laboratory Services and Applied Science Division: Athens, GA, USA, 2020.

40. Bergmann, M.; Mützel, S.; Primpke, S.; Tekman, M.; Trachsel, J.; Gerdts, G. White and wonderful? Microplastics prevail in snow from the Alps to the Arctic. Sci. Adv. 2019, 5, eaax1157. [CrossRef] [PubMed]

41. Anuar Sharuddin, S.D.; Abnisa, F.; Wan Daud, W.M.A.; Aroua, M.K. Energy recovery from pyrolysis of plastic waste: Study on non-recycled plastics (NRP) data as the real measure of plastic waste. Energy Convers. Manag. 2017, 148, 925-934. [CrossRef]

42. Wagner, S.; Hüffer, T.; Klöckner, P.; Wehrhahn, M.; Hofmann, T.; Reemtsma, T. Tire wear particles in the aquatic environment-A review on generation, analysis, occurrence, fate and effects. Water Res. 2018, 139, 83-100. [CrossRef] [PubMed]

43. Li, B.; Pales, A.R.; Clifford, H.M.; Kupis, S.; Hennessy, S.; Liang, W.; Moysey, S.; Powell, B.; Finneran, K.T.; Darnault, C.J.G. Preferential flow in the vadose zone and interface dynamics: Impact of microbial exudates. J. Hydrol. 2018, 558, 72-89. [CrossRef]

44. Zhou, Y.; Wang, J.; Zou, M.; Jia, Z.; Zhou, S.; Li, Y. Microplastics in soils: A review of methods, occurrence, fate, transport, ecological and environmental risks. Sci. Total Environ. 2020, 748, 141368. [CrossRef]

45. Huang, Y.; Liu, Q.; Jia, W.; Yan, C.; Wang, J. Agricultural plastic mulching as a source of microplastics in the terrestrial environment. Environ. Pollut. 2020, 260, 114096. [CrossRef]

46. Maaß, S.; Daphi, D.; Lehmann, A.; Rillig, M.C. Transport of microplastics by two collembolan species. Environ. Pollut. 2017, 225, 456-459. [CrossRef]

47. Ryan, P.G.; Moore, C.J.; van Franeker, J.A.; Moloney, C.L. Monitoring the abundance of plastic debris in the marine environment. Series B Biol. Sci. 2009, 364, 1999-2012. [CrossRef]

48. Xu, S.; Ma, J.; Ji, R.; Pan, K.; Miao, A. Microplastics in aquatic environments: Occurrence, accumulation, and biological effects. Sci. Total Environ. 2020, 703, 134699. [CrossRef]

49. Peng, J.; Wang, J.; Cai, L. Current understanding of microplastics in the environment: Occurrence, fate, risks, and what we should do. Integr. Environ. Assess Manag. 2017, 13, 476-482. [CrossRef] [PubMed]

50. Nizzetto, L.; Bussi, G.; Futter, M.N.; Butterfield, D.; Whitehead, P.G. A theoretical assessment of microplastic transport in river catchments and their retention by soils and river sediments. Environ. Sci.: Process Impacts 2016, 18, 1050-1059. [CrossRef] [PubMed]

51. Da Costa, J.P.; Santos, P.S.; Duarte, A.C.; Rocha-Santos, T. (Nano) plastics in the environment-sources, fate and effects. Sci. Total Environ. 2016, 566-567, 15-26. [CrossRef]

52. Chae, Y.; An, Y.J. Current research trends on plastic pollution and ecological impacts on the soil ecosystem: A review. Environ. Pollut. 2018, 240, 387-395. [CrossRef] [PubMed]

53. Rillig, M.C.; Ziersch, L.; Hemplel, S. Microplastic transport in soil by earthworms. Sci. Rep. 2017, 7, 1362-1367. [CrossRef]

54. Rodriguez-Seijo, A.; Lourenço, J.; Rocha-Santos, T.A.P.; da Costa, J.; Duarte, A.C.; Vala, H.; Pereira, R. Histopathological and molecular effects of microplastics in Eisenia andrei Bouche. Environ. Pollut. 2017, 220, 495-503. [CrossRef] [PubMed]

55. Hodson, M.E.; Duffus-Hodson, C.A.; Clark, A.; Prendergast-Miller, M.T.; Thorpe, K.L. Plastic bag derived-microplastics as a vector for metal exposure in terrestrial invertebrates. Environ. Sci. Technol. 2017, 51, 4714-4721. [CrossRef]

56. Bagchia, S.; Probasco, S.; MardanDoost, B.; Sturma, B.S.M. Fate of Microplastics in Water Resource Recovery Facilities (WRRFs) and National Environmental Loading Estimates. Proc. Water Environ. Fed. 2016, 2016, 353-361. [CrossRef] 
57. Mintenig, S.M.; Int-Veena, I.; Löder, M.G.J.; Primpke, S.; Gerdts, G. Identification of microplastic in effluents of waste water treatment plants using focal plane array-based micro-Fourier-transform infrared imaging. Water Res. 2017, 108, 365-372. [CrossRef]

58. Baldwin, A.K.; Corsi, S.R.; Mason, S.A. Plastic Debris in 29 Great Lakes Tributaries: Relations to Watershed Attributes and Hydrology. Environ. Sci. Technol. 2016, 50, 10377-10385. [CrossRef]

59. de Sá, L.C.; Oliveira, M.; Ribeiro, F.; Rocha, T.L.; Futter, N. Studies of the effects of microplastics on aquatic organisms: What do we know and where should we focus our efforts in the future? Sci. Total Environ. 2018, 645, 1029-1039. [CrossRef] [PubMed]

60. Fok, L.; Cheung, P.K.; Tang, G.; Li, W.C. Size distribution of stranded small plastic debris on the coast of Guangdong, South China. Environ. Pollut. 2017, 220, 407-412. [CrossRef] [PubMed]

61. Fairbrother, A.; Hsueh, H.; Kim, J.H.; Jacobs, D.; Perry, L.; Goodwin, D.; White, C.; Watson, S.; Sung, L. Temperature and light intensity effects on photodegradation of high-density polyethylene. Polym. Degrad. Stabil. 2019, 165, 153-160. [CrossRef]

62. Xu, B.L.; Liu, F.; Cryder, Z.; Huang, D.; Lu, Z.J.; He, Y.; Wang, H.Z.; Lu, Z.M.; Brookes, P.C.; Tang, C.X.; et al. Microplastics in the soil environment: Occurrence, risks, interactions and fate-A review. Crit. Rev. Environ. Sci. Technol. 2019, 2175-2222. [CrossRef]

63. Bandow, N.; Will, V.; Wachtendorf, V.; Simon, F. Contaminant release from aged microplastic. Environ. Chem. 2017, 14, 394-405. [CrossRef] 